\title{
"COISA DE MENINO, COISA DE MENINA" - O PAPEL DA EDUCAÇÃO FÍSICA NA COMPREENSÃO DAS RELAÇÕES DE GÊNERO COMO BASE PARA UMA EDUCAÇÃO INCLUSIVA
}

\author{
BOY THING, GIRL THING "- THE ROLE OF PHYSICAL EDUCATION IN THE \\ UNDERSTANDING OF GENDER RELATIONS AS A BASIS FOR INCLUSIVE \\ EDUCATION
}

\author{
F. P. CARBALLO ${ }^{*}$, A. P. M. FONSECA ${ }^{1}$, P. S. S. FERREIRA ${ }^{1}$, J. A. R. NETO ${ }^{1}$ \\ 1 Universidade do Estado de Minas Gerais-UEMG-MG, Brasil
}

ARTICLE INFO

Article history:

Received 2018-07-12

Accepted 2018-12-20

Available online 2018-12-21

*Autor correspondente:

E-mail:peronmg@hotmail.com
Palavras-chave: Educação Física Escolar. Gênero. Relação.

Keywords: Physical School Education. Genre. Relationship.

RESUMO. Atualmente, percebe-se que os debates envolvendo Gênero têm dividido opiniões, em qualquer instância social. Em relação à educação, segundos os $P C N^{\prime}$ 's e a $L D B$ em seu Art. $3^{\circ}$ § IV este debate é visto como um compromisso, por meio do conteúdo Orientação Sexual .A construção do que é pertencer a um ou outro sexo, se dá pelo tratamento diferenciado para meninos ou meninas, inclusive nas expressões diretamente ligadas à sexualidade e pelos padrões socialmente estabelecidos. Em relação à Educação Física, inserida nesse contexto, deve cumprir um dos objetivos gerais no ensino fundamental, que é por meio de sua práxis levar os alunos a participar de atividades corporais, estabelecendo relações equilibradas e construtivas com os outros, reconhecendo e respeitando características físicas e de desempenho de si próprio e dos outros, sem discriminar por características pessoais, físicas, sexuais ou sociais. Diante disto, o intuito deste trabalho é averiguar o quanto os alunos são influenciados pelos conceitos culturais que estabelecem o que é adequado em relação ao gênero e se agem em conformidade a eles. Trata-se de uma pesquisa quanti-qualitativa, por meio da aplicação de um questionário a alunos do sétimo ao nono anos de escolas públicas da Cidade de Cláudio. Os resultados apontam que esse tema tem que ser mais debatido e aprofundado em todos os segmentos educacionais.

\begin{abstract}
Nowadays, it is perceived that the debates involving Gender have divided opinions, in any social instance. Regarding education, second the PCN'Ss and LDB in its Art. $3^{\circ} \S \mathrm{IV}$ this debate is seen as a compromise, through the content Sexual Orientation. The construction of what is to belong to either sex, is given by the differential treatment for boys or girls, including expressions directly related to sexuality and socially established patterns. In relation to Physical Education, inserted in this context, it must fulfill one of the general objectives in elementary education, which is through its praxis to lead students to participate in bodily activities, establishing balanced and constructive relationships with others, recognizing and respecting physical characteristics and performance of self and others, without discrimination for personal, physical, sexual or social characteristics. In view of this, the purpose of this work is to investigate how the students are influenced by the cultural concepts that establish what is appropriate in relation to the genre and act accordingly. This is a qualitative research, through the application of a questionnaire to students from the seventh to the ninth year of public schools in the City of Cláudio. The results point out that this theme has to be more debated and deepened in all educational segments.
\end{abstract}




\section{Introdução}

Os debates realizados nos últimos tempos em diversas instâncias da sociedade envolvendo Gênero têm dividido opiniões. No entanto, em âmbito escolar os debates iniciam, ou deveriam iniciar, por meio do conteúdo Orientação Sexual, entendido como "[...] processo de intervenção pedagógica que tem como objetivo transmitir informações e problematizar questões relativas à sexualidade, incluindo posturas, crenças, tabus e valores a ela associados" (BRASIL, 2011, p. 34). Também, faz-se necessário que a educação cumpra as deliberações da Lei de Diretrizes e Bases da Educação (LDB - Lei 9.394/96), que assevera em seu Art. $3^{\circ} \S \mathrm{IV}$, que "O ensino será ministrado com base [...] no respeito à liberdade e no apreço à tolerância" - sendo sempre contra todo tipo de discriminação e preconceito.

O debate sobre Gênero como compromisso da Educação, é previsto nos PCN's (Parâmetros Curriculares Nacionais), que definem a si próprios como "[...] referencial de qualidade para a Educação no Ensino Fundamental em todo o País". (BRASIL, 2001, p. 45), e estão incluídos nas propostas de discussão em sala de aula, inserindo-se em conteúdos cujas temáticas lidam com o desenvolvimento humano, como "[...] Ética, Meio Ambiente, Pluralidade Cultural, Saúde e Orientação Sexual." (BRASIL, 2011, p. 29) - propondo que esta abordagem seja feita de modo "[...] não diretivo". (BRASIL 2001, p.121), a partir da Transversalidade, que, dada "[...] a complexidade [inerente a cada um desses assuntos] faz com que nenhuma das áreas, isoladamente, seja suficiente para abordá-los". (BRASIL, 2011, p. 36). Assim, discutir sobre Relações de Gênero em sala de aula tem como objetivo o "[...] o questionamento de papéis rigidamente estabelecidos a homens e mulheres, a valorização de cada um e a flexibilização desses papéis". (BRASIL 2001, p. 35).

Nesse processo, o professor deve "[...] ter postura pluralista e democrática, o que cria condições mais favoráveis para o esclarecimento e informação sem a imposição de valores particulares". (BRASIL, 2001, p. 153), além de sempre [...] se mostrar disponível para conversar a respeito das questões apresentadas, não emitir juízo de valor, [...] responder as perguntas de forma direta e esclarecedora [...] [oferecendo] informações corretas do ponto de vista científico, [prestando] esclarecimentos sobre as questões trazidas pelos alunos, fundamentais para seu bem-estar e tranquilidade (BRASIL, 2011, p. 124).

Além disso, a Educação Sexual Escolar, tratada como Orientação Sexual nos PCN's, tem por meta "[...] promover reflexões e discussões de técnicos, professores, equipes pedagógicas, bem como com pais e responsáveis com a finalidade de sistematizar a ação pedagógica no desenvolvimento dos alunos, levando em conta os princípios morais de cada um dos envolvidos e respeitando também os Direitos Humanos" (BRASIL 2001, p. 107). 
Em relação à Educação Física inserida nesse contexto é entendida como "[...] cultura corporal [...] no que tange à questão de gênero [deve] [...] dar oportunidade para que meninos e meninas convivam, observem-se, descubram-se e possam aprender a ser tolerantes, a não discriminar e a compreender as diferenças, de forma a não reproduzir estereotipadamente relações sociais autoritárias" (BRASIL, 2001, p. 25-30).

A Declaração Universal dos Direitos Humanos, proclamada pela Assembleia Geral das Nações Unidas em Paris, em 10 de Dezembro de 1948, assevera que "[...] 0 reconhecimento da dignidade inerente a todos os membros da família humana e dos seus direitos iguais e inalienáveis constitui o fundamento da liberdade, da justiça e da paz no mundo". De modo, que ao abordar assuntos inerentes ao ser humano, é preciso enfatizar o documento supracitado, cujos paradigmas jamais apoiam um grupo humano em detrimento de outro, sendo que também o "[...] o professor deve ter discernimento para não transmitir seus valores, crenças e opiniões como sendo princípios ou verdades absolutas" (BRASIL, 2001, p. 123).

De fato, o artigo 5ำ $\S$ VI, da Constituição Federal de 1988, diz que "É inviolável a liberdade de consciência e de crença[...]" - o que caracteriza o Estado como laico, evidenciando que crenças particulares não devam ser levadas em conta quando se trata de discutir assuntos que interessam ao coletivo (marcado pela diversidade cultural e religiosa). A propósito, a constante interferência religiosa que se verifica a nível municipal, estadual e federal, no que diz respeito às relações de gênero, não deve encontrar eco dentro da escola.

De fato, por ocasião da aprovação dos Planos Decenais de Educação (PNE - Lei no 13.005, de 25 de junho de 2014), que determina diretrizes, estratégias e metas a serem atingidas pela esta ao longo de dez anos, alguns parlamentares, segundo Britto e Reis (2015, p. 23), "pressionados pelas bancadas religiosas, e com o respaldo das igrejas evangélicas e católica, [...] retiraram dos Planos Estaduais de Educação referências à identidade de gênero, diversidade e orientação sexual. [...] Entre os trechos vetados estão metas de combate à 'discriminação racial, de orientação sexual e à identidade de gênero', censos sobre situação educacional de travestis e transgêneros e incentivo a programas de formação sobre gênero, diversidade e orientação sexual".

Em contrapartida, o MEC (Ministério da Educação e Cultura), divulgou uma nota logo depois (nota técnica nำ24/2015), defendendo a inclusão de gênero e orientação sexual nas pautas de discussão dos planos de educação estaduais e municipais, a qual dizia:

[...] é preciso reafirmar que os conceitos de gênero e orientação sexual, sem negar-Ihes sua relevância política; são conceitos científicos construídos em bases acadêmicas. Os estudos de gênero e sexualidade formam um campo de pesquisa e produção de conhecimento reconhecido internacionalmente, apropriado no Brasil desde a década de 1970. Há mais de 1.000 grupos de pesquisa cadastrados no Conselho Nacional de 
Desenvolvimento Científico e Técnico (CNPq) que tem gênero como um eixo de estudo [...] Os conceitos de gênero e orientação sexual podem ajudar a compreender as desigualdades históricas entre homens e mulheres, além de ser central na compreensão (e enfrentamento) de diferentes formas de discriminação e violência, incluídos o machismo, o sexismo, a homofobia, o racismo e a transfobia, que se reproduzem também em espaços escolares (MINISTÉRIO DA EDUCAÇÃO E CULTURA, NOTA TÉCNICA №24/2015).

Abordar este tema nos anos finais do Ensino Fundamental é importante porque os alunos que integram o $4^{\circ}$ Ciclo, que compreende os $7^{\circ}, 8^{\circ}$ e $9^{\circ}$ Anos estão na faixa etária de 12 a 15 anos, e, ou seja, na fase de puberdade. Nesse sentido,

quando ocorrem [...] as mudanças físicas [que] incluem alterações hormonais [quando] [...] os alunos também já trazem questões mais polêmicas em sexualidade, [e] já apresentam necessidade e melhores condições de refletir sobre temáticas como aborto, virgindade, homossexualidade, pornografia, prostituição e outras (BRASIL, 2001, p. 118-129).

Sendo assim, o presente trabalho pretende abordar as relações de gênero, buscando aferir o nível de percepção dos alunos frente à diversidade que compõe a sociedade e a escola.

\section{Metodologia}

Para a realização deste trabalho optou-se por uma pesquisa quanti-qualitativa, pela necessidade de contabilizar dados e por envolver a percepção de pessoas sobre a importância do assunto da pesquisa.

As pesquisas quantitativas baseiam seus estudos em análise de características diferenciadas e numéricas, geralmente ao longo de alguma dimensão, entre dois ou mais grupos, procurando provar a existência de relações entre variáveis. As pesquisas qualitativas são subjetivas, tendo um caráter exploratório, uma vez que há uma estimulação para que as pessoas pensem e falem livremente sobre o assunto em questão (SILVEIRA, 2004, p 107).

Sendo assim, optou-se pela elaboração de um questionário de múltipla escolha com quatro questões referentes ao tema a ser aplicados nas escolas públicas, municipais e estaduais da cidade de Cláudio em alunos do $7^{\circ}$, $8^{\circ}$ e $9^{\circ}$ anos, a fim de verificar a percepção deles acerca do tema. Antes dessa etapa, foi agendada uma visita a cada diretor, houve apresentação do questionário e explicação sobre a intenção do mesmo, bem como sobre os objetivos gerais e específicos. Foi requisitado de cada aluno durante o processo de 
preenchimento, que não se comunicassem com os colegas, a fim de garantir a exatidão à cada parecer conforme a própria compreensão dos alunos.

\section{Resultados e Discussão}

Comparando-se os alunos do $7^{\circ}$ Ano em sua totalidade (das três escolas), constatouse que $28 \%$ (13) dos meninos e $26 \%$ (12) das meninas associam Gênero ao sexo biológico. Outros 24\% (11) dos meninos e 20\% (09) das meninas acham que gênero se refira à orientação sexual. E 46\% (21) dos meninos e 53\% (24) das meninas entendem que gênero se refere aos comportamentos que se considera adequados para uma pessoa dependendo se é homem ou mulher. Tomando-se todos os alunos em conjunto, contando-se meninos e meninas, $50 \%$ (45) foram os que entendem que gênero se refere aos comportamentos que se considera adequados para uma pessoa dependendo se é homem ou mulher. Os $50 \%$ (45) restantes foram os que optaram pelas outras opções (Gráfico 1).

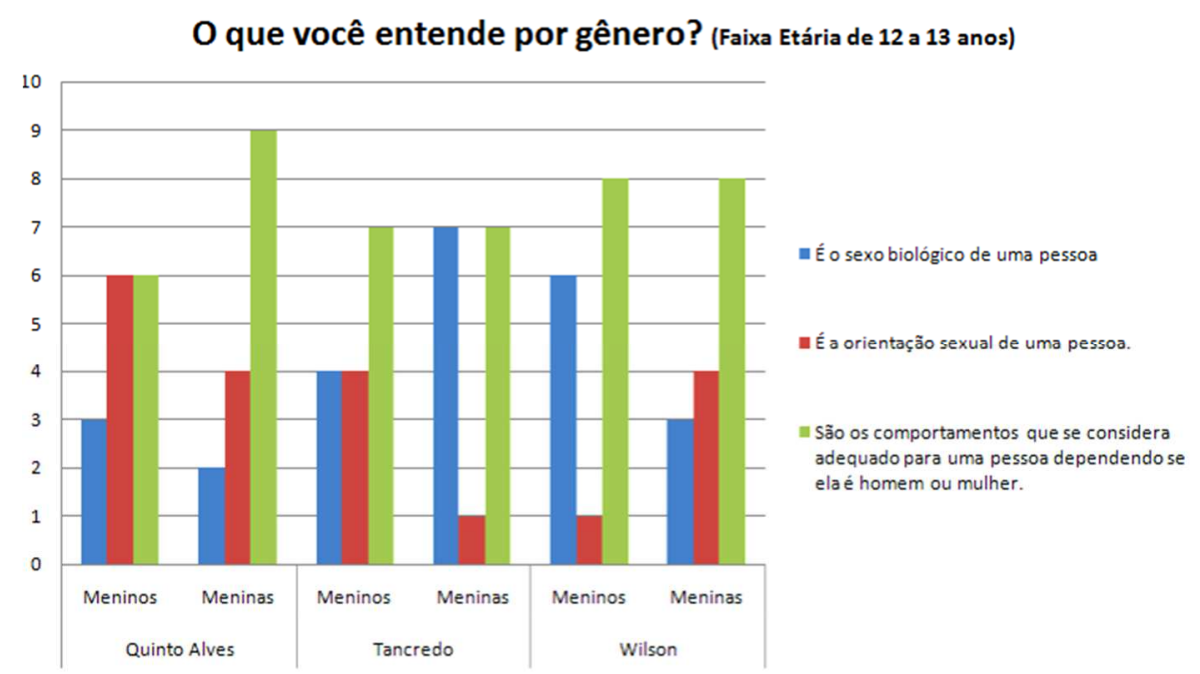

Gráfico 1 - 0 que você entende por gênero? (Alunos do 7ํAno). Fonte: Os autores (2018).

Comparando-se os alunos do $8^{\circ}$ Ano em sua totalidade (das três escolas), constatouse que 35\% (16) dos meninos e 31\% (14) das meninas associam Gênero ao sexo biológico. Outros $26 \%$ (12) dos meninos e $31 \%$ (14) das meninas acham que gênero se refira à orientação sexual. E 37\% (17) dos meninos e 37\% (17) das meninas entendem que gênero se refere aos comportamentos que se considera adequados para uma pessoa dependendo se é homem ou mulher. Tomando-se todos os alunos em conjunto, contando-se meninos e meninas, $37 \%$ (34) foram os que entendem que gênero se refere aos comportamentos que se considera adequados para uma pessoa dependendo se é homem ou mulher. Os $62 \%$ (56) restantes foram os que optaram pelas outras opções (Gráfico 2). 


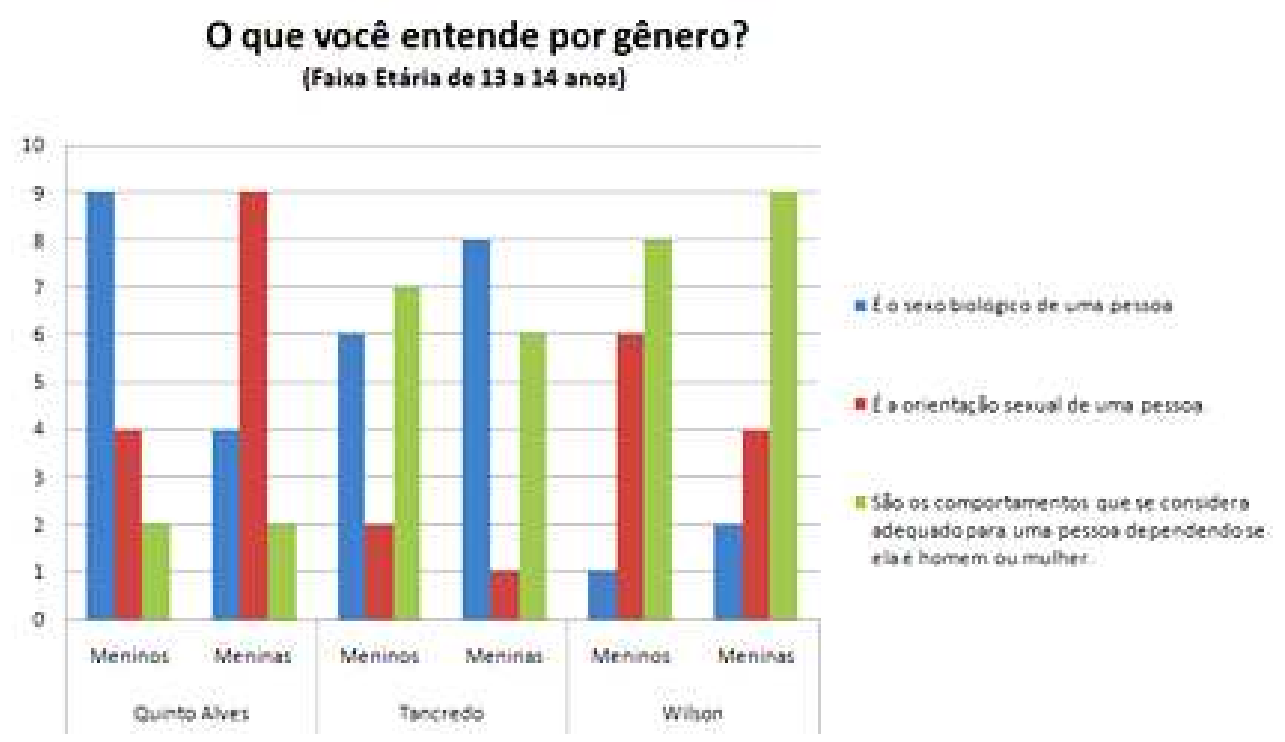

Gráfico 2 - O que você entende por gênero? (Alunos do 8으스. Fonte: Os autores (2018).

Comparando-se os alunos do 9 Ano em sua totalidade (das três escolas), constatouse que 44\% (20) dos meninos e 57\% (26) das meninas associam Gênero ao sexo biológico. Outros 26\% (12) dos meninos e 28\% (13) das meninas acham que gênero se refira à orientação sexual. E 28\% (13) dos meninos e 13\% (06) das meninas entendem que gênero se refere aos comportamentos que se considera adequados para uma pessoa dependendo se é homem ou mulher. Tomando-se todos os alunos em conjunto, contando-se meninos e meninas, $21 \%$ (19) foram os que entendem que gênero se refere aos comportamentos que se considera adequados para uma pessoa dependendo se é homem ou mulher. Os $80 \%$ (72) restantes foram os que optaram pelas demais alternativas (Gráfico 3).

\section{O que você entende por gênero? (Faixa Etária de 14 a 15 anos)}

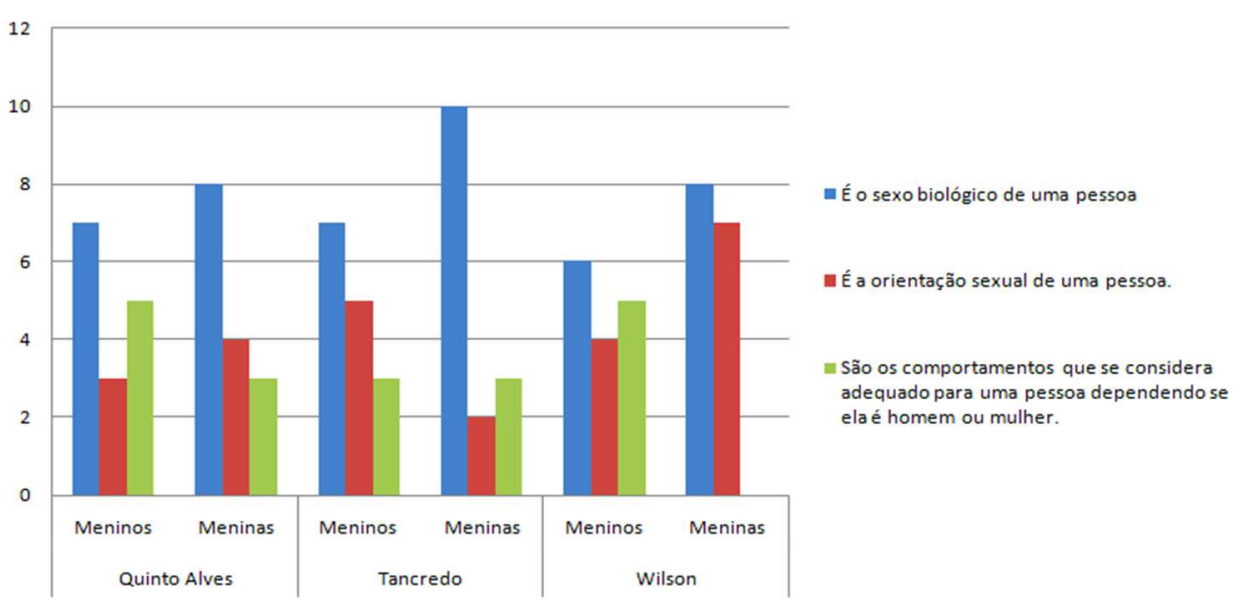

Gráfico 3 - 0 que você entende por gênero? (Alunos da 9ํAo). Fonte: Os autores (2018). 
Na questão acima, apenas 2\% (01) dos meninos e 4\% (4) das meninas acham que cozinhar, lavar e cuidar da estética são atividades adequadas apenas para homens. Somente 2\% (01) das meninas disseram que é cozinhar, lavar e pilotar aviões. Outros $22 \%$ (10) dos meninos (as meninas não opinaram nesta) disseram pilotar aviões, liderar grandes empresas e jogar futebol. Outros $75 \%$ (34) dos meninos e 93\% (42) das meninas disseram que homens e mulheres podem fazer quaisquer atividades.

O percentual de alunos, contando-se os meninos e as meninas, que pensam que homens e mulheres podem fazer quaisquer coisas foi de $94 \%$ (76). Apenas $15 \%$ (14) entre meninos e meninas acham que somente algumas das atividades enumeradas são adequadas para homens (Gráfico 4).

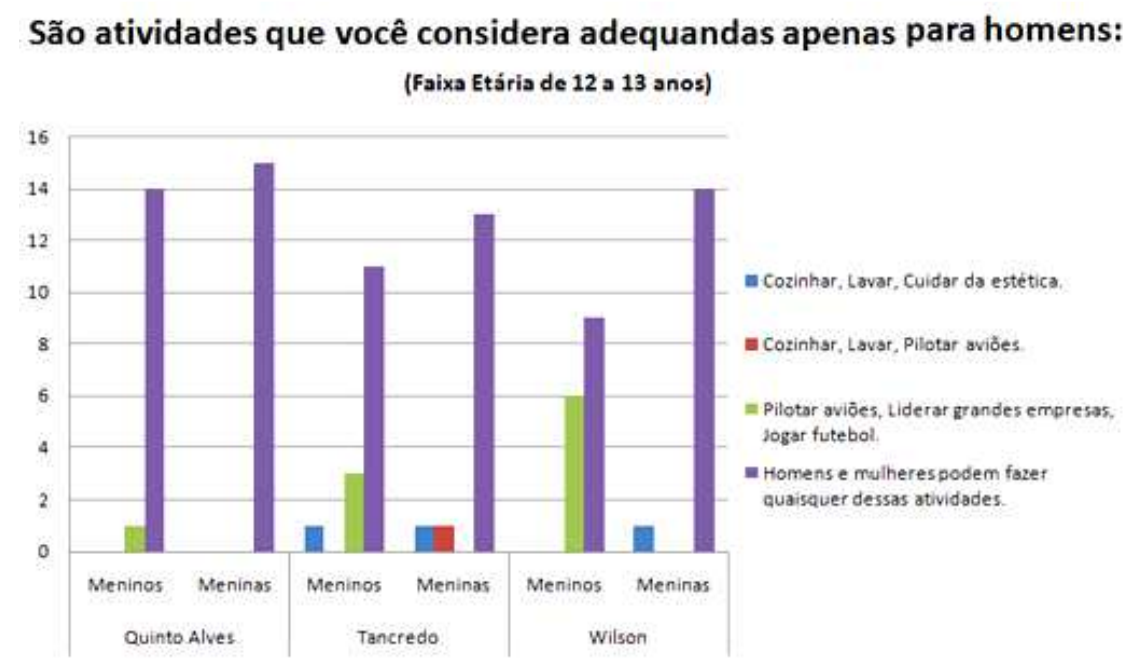

Gráfico 4 - São atividades que você considera adequadas apenas para homens. (Alunos do 7으으.

Fonte: Os autores (2018).

Os alunos do $8^{\circ}$ ano se dividiram em apenas duas opções. Assim, 13\% (06) dos homens e 06\% (03) das meninas disseram que pilotar aviões, liderar grandes empresas e jogar futebol são atividades apenas para homens, enquanto $86 \%$ (39) dos meninos e $93 \%$ (42) das meninas disseram que homens e mulheres podem fazer quaisquer atividades. Tomando-se o percentual geral de meninos e meninas, 90\% (81) concordam que homens e mulheres podem fazer quaisquer atividades. Apenas 10\% (09) dos alunos marcaram outras opções (Gráfico 5). 
São atividades que você considera adequadas apenas para homens:

(Faixa Etária de 13 a 14 anos)

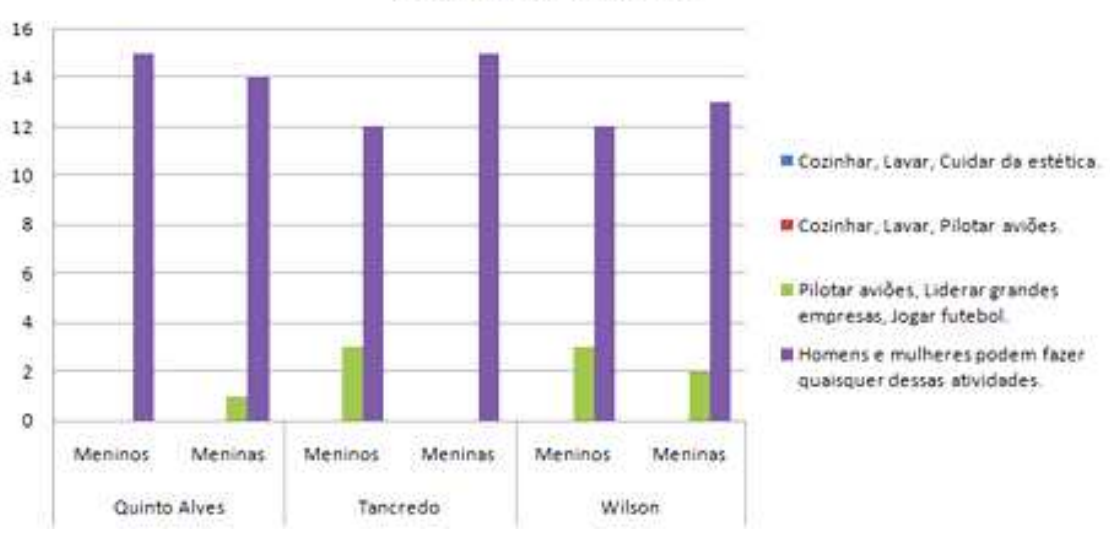

Gráfico 5 - São atividades que você considera adequadas apenas para homens (Alunos da $8^{\mathrm{a}}$ série).

Fonte: Os autores (2018).

Entre os alunos do 9a ano, apenas 02\% (01) menina concorda que cozinhar, lavar e cuidar da estética seja atividade adequada apenas para homens. Outra menina $02 \%(01)$ acha que seja cozinhar, lavar e pilotar aviões. 13\% (06) dos meninos e 02\% (01) das meninas concordam que seja pilotar aviões, liderar grandes empresas e jogar futebol. No entanto, $86 \%$ (39) dos meninos e 93\% (42) das meninas disseram que homens e mulheres podem fazer quaisquer atividades. Tomando-se o percentual geral de meninos e meninas, 90\% (81) dos alunos concordam que homens e mulheres podem fazer quaisquer atividades (curiosamente o mesmo percentual da turma anterior, do 8 Ano). Apenas 10\% (09) dos alunos optaram pelas demais alternativas (Gráfico 6).

São atividades que você considera adequadas apenas

para homens: (Faixa Etária de 14 a 15 anos)

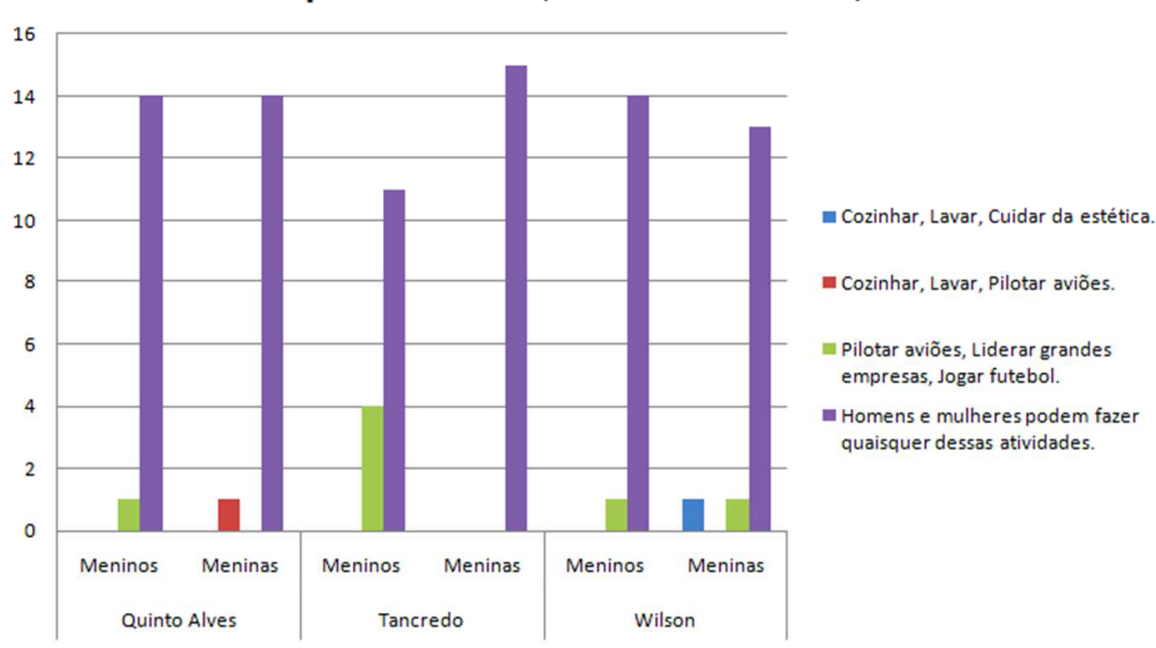

Gráfico 6 - São atividades que se considera adequadas apenas para homens. (Alunos da 9 Ano).

Fonte: Os autores (2018). 
Entre os alunos de 7ํㅡㄹ Ano, apenas 02\% (01) dos meninos e 04\% (02) das meninas disseram que as atividades esportivas adequadas apenas para mulheres são vôlei, futebol e pilates. Outros 17\% (08) dos meninos e 06\% (03) das meninas acreditam que seja vôlei, pilates e peteca. Apenas 04\% (02) dos meninos escolheram futebol, boxe e pilates. No entanto, $75 \%$ (34) dos meninos e $88 \%$ (40) das meninas disseram que mulheres e homens podem fazer quaisquer atividades que desejem. Tomando-se o percentual geral de meninos e meninas, $82 \%$ (74) optaram pela liberdade de escolha de atividades enquanto apenas 17\% (16) delimitaram uma determinada atividade de acordo com o sexo (Gráfico 7).

São atividades desportivas adequadas apenas para

mulheres: (Faixa Etária de 12 a 13 anos)

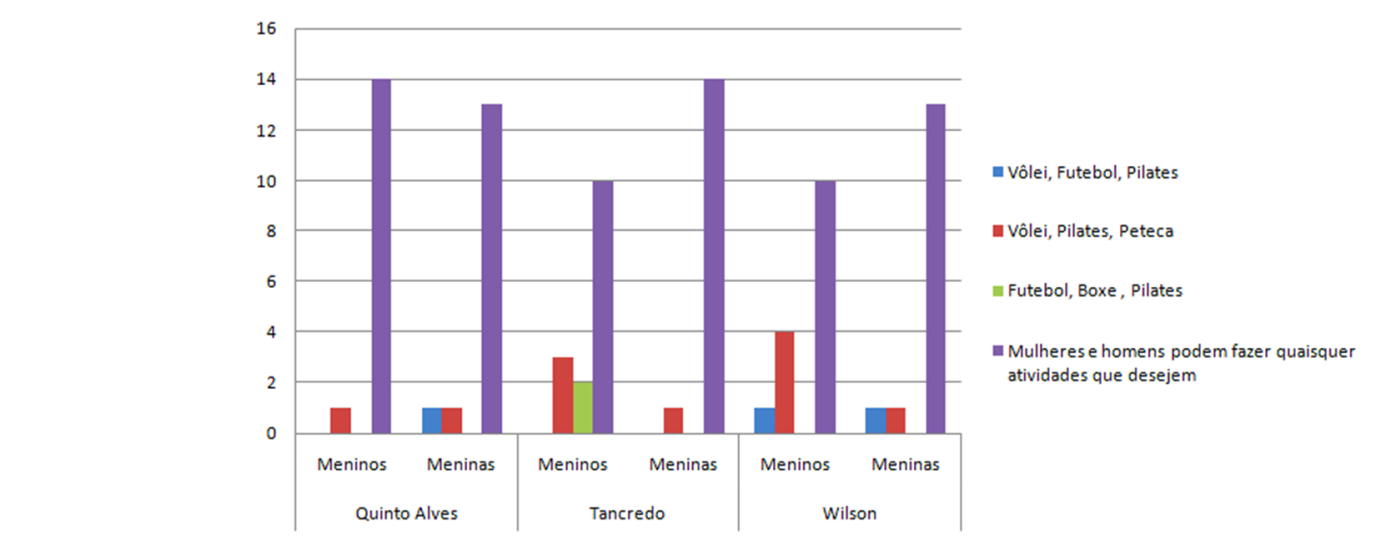

Gráfico 7 - São atividades desportivas adequadas apenas para mulheres (Alunos do $7^{\circ}$ Ano).

Fonte: Os autores (2018).

Entre os alunos do 8 Ano, apenas 02\% (01) dos meninos e 02\% (01) meninas disseram que Vôlei, futebol e pilates são atividades adequadas apenas para mulheres. Outros 15\% (07) dos meninos e 02\% (01) entre as meninas disseram ser vôlei, pilates e peteca. No entanto, $84 \%$ (38) dos meninos e 93\% (42) das meninas acham que homens e mulheres têm liberdade de escolha de atividades, enquanto apenas 11\% (10) dos alunos optaram por delimitar determinadas atividades. O percentual de alunos, somando-se meninos e meninas, que optaram pela liberdade de escolha de atividades é de $88 \%$ (80) alunos. O percentual dos que pensam que apenas algumas atividades são adequadas para mulheres é de apenas 11\% (10) alunos (Gráfico 8). 
São atividades desportivas adequadas apenas para

mulheres: (Faixa Etária de 13 a 14 anos)

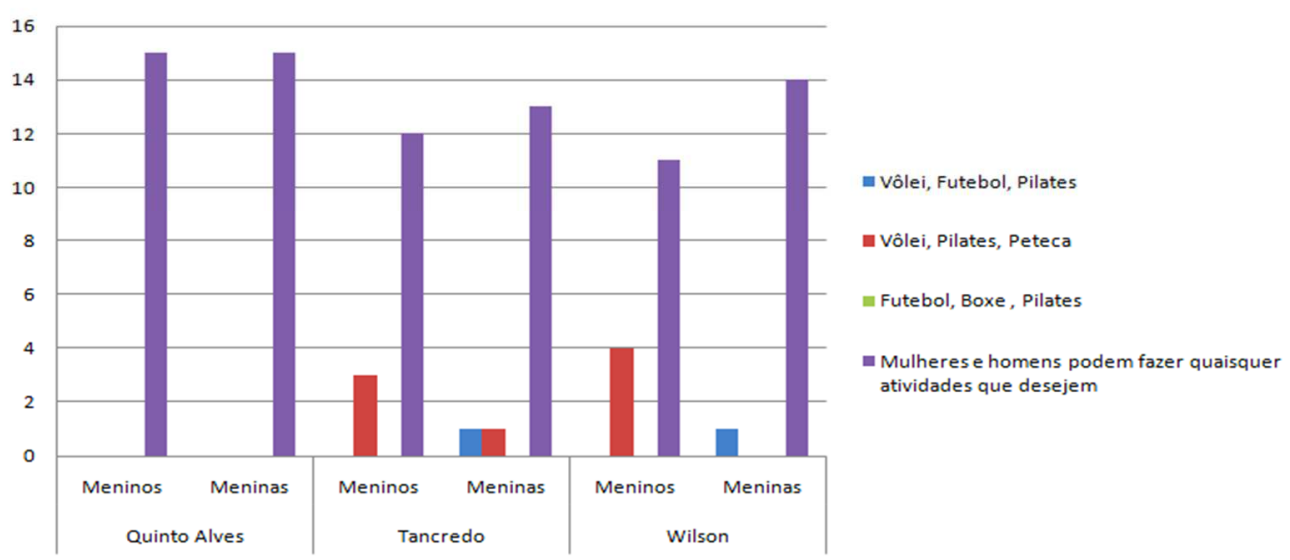

Gráfico 8 - São atividades desportivas adequadas apenas para mulheres (Alunos da 8은 Ano).

Fonte: Os autores (2018).

Entre os alunos do 9 Ano, apenas $02 \%$ (01) dos meninos marcaram vôlei, futebol e pilates como atividades adequadas apenas para mulheres. Outros 17\% (08) dos meninos e 04\% (02) das meninas marcaram vôlei, pilates e peteca. No entanto, 80\% (36) dos meninos e 95\% (43) das meninas acham que homens e mulheres têm liberdade de escolha de atividades. O percentual de alunos, somando-se meninos e meninas, que optaram pela liberdade de escolha de atividades é de $87 \%$ (90). O percentual dos que optaram por determinadas atividades é de apenas 12\% (11) (Gráfico 9).

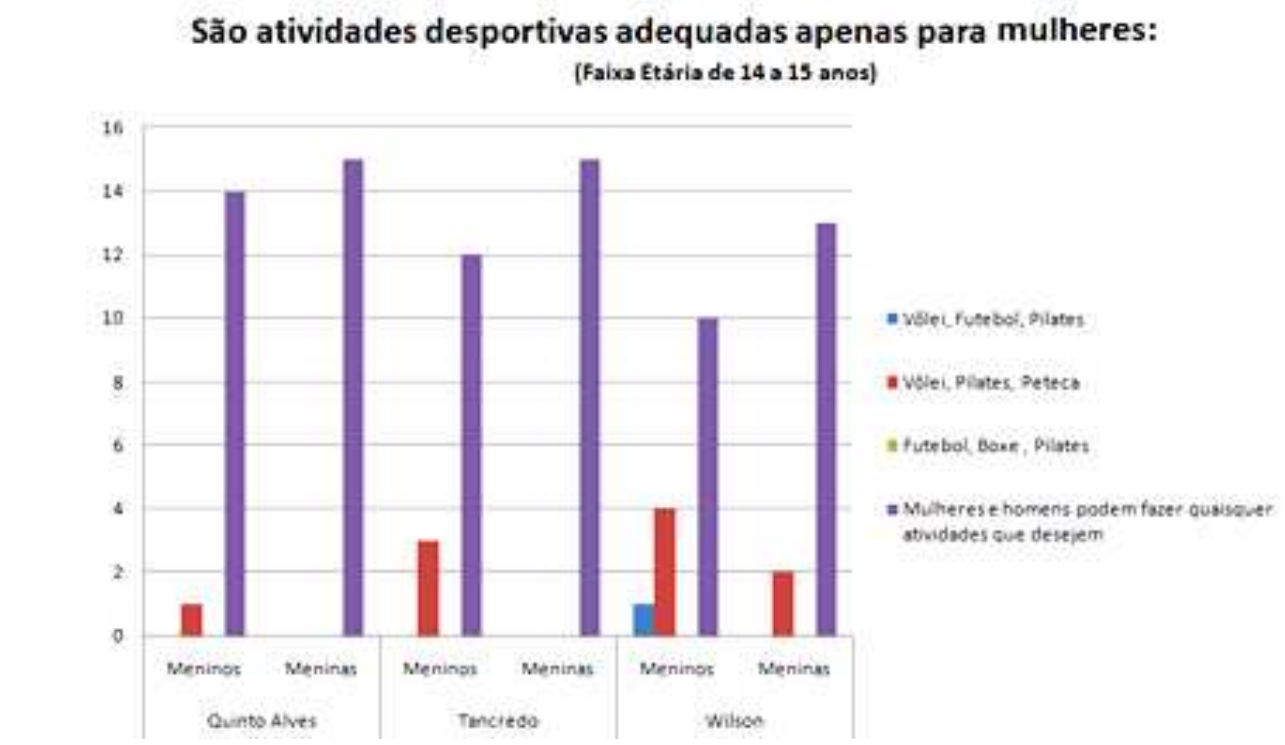

Gráfico 9 - São atividades desportivas adequadas apenas para mulheres. Fonte: Os autores (2018). 
No quadro acima, os alunos do $7^{\circ}$ Ano, $51 \%$ (23) dos meninos e $46 \%$ (21) das meninas pensam que as aulas de educação física devem ser mistas. Outros 20\% (09) dos meninos e $13 \%$ (06) das meninas acham que as aulas devem ser separadas - porque as meninas são mais frágeis que os meninos. No entanto, outros $13 \%(06)$ dos meninos e $02 \%$ (01) das meninas pensam que devem ser separadas - pois cada pessoa deve fazer atividades que tenham a ver com seu sexo.

Outros 24\% (11) dos meninos e $37 \%$ (17) das meninas concordam em que as atividades devem ser mistas - mas com adaptação das regras para favorecer as meninas. Nas alternativas que tiveram mais votações, temos que (somando-se meninos e meninas) $48 \%$ (44) dos alunos concordam que as atividades devem ser mistas. E outros $26 \%$ (24) dos alunos pensam que as aulas devem ser mistas - mas com adaptação das regras para atender às meninas. Os restantes $23 \%$ (21) alunos se dividiram entre as duas outras opções (Gráfico 10).

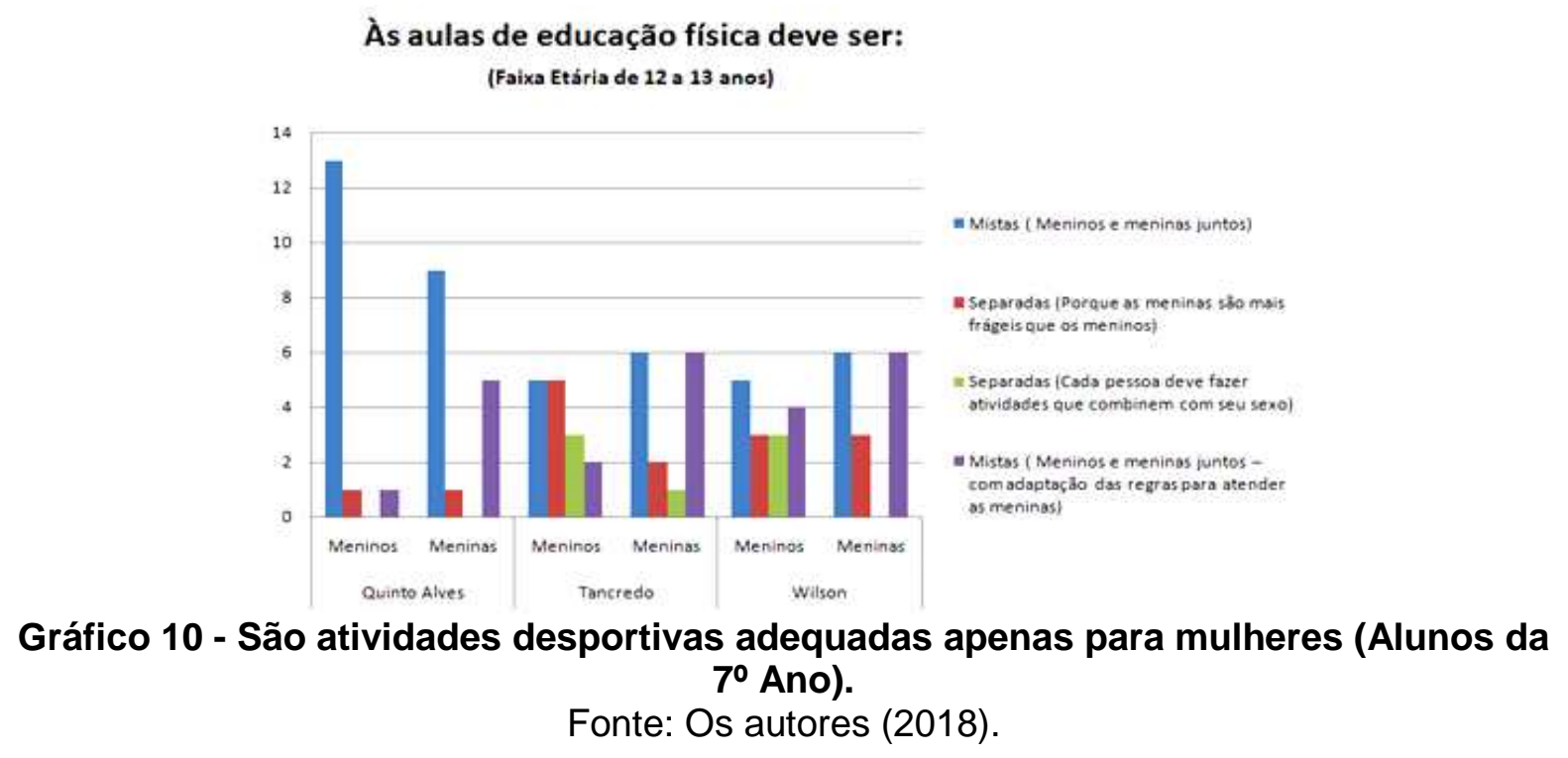

Entre os alunos do 8ㅇ Ano, 37\% (17) dos meninos e 64\% (29) das meninas acham que as aulas de educação física devem ser mistas. 22\% (10) dos meninos e 02\% (01) das meninas acham que as aulas devem ser separadas - porque as meninas são mais frágeis que os meninos. Apenas 04\% (02) dos meninos marcaram que as atividades têm que ser separadas - porque cada pessoa tem que fazer atividades adequadas ao próprio sexo. 33\% (15) dos meninos e 33\% (15) das meninas concordam que as atividades têm que ser mistas - com adaptação das regras para atender as meninas.

Nas alternativas que tiveram mais votações, somando-se os alunos de ambos os sexos em todas as turmas, $51 \%$ (46) dos alunos concordam que as atividades devem ser mistas; $33 \%$ (30) dos alunos concordam em que as aulas devem ser mistas com adaptação de regras para favorecer as meninas (Gráfico 11). 
Às aulas de educação física devem ser:

(Faixa Etária de 13 a 14 anos)

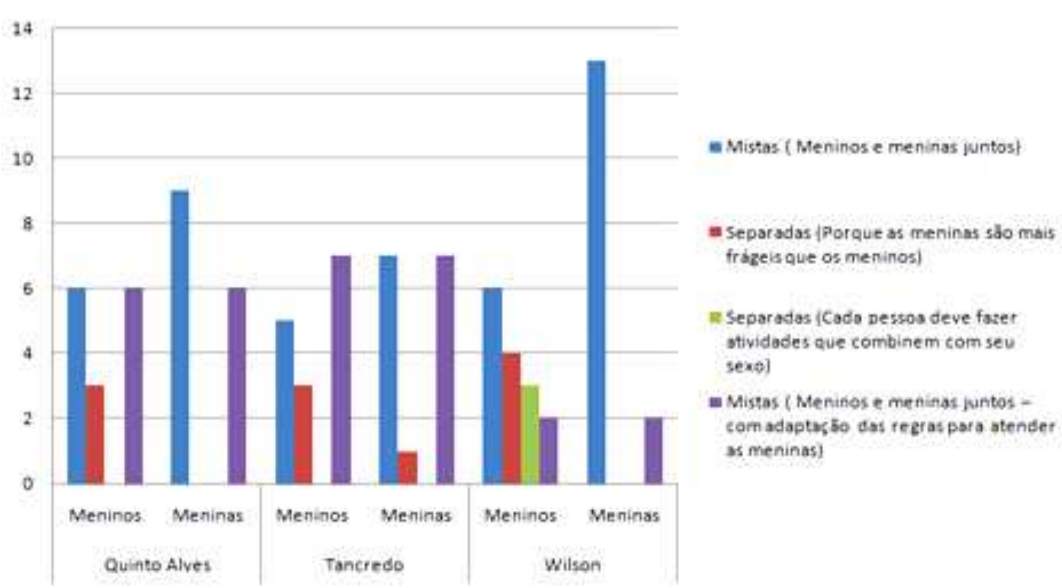

Gráfico 11 - São atividades desportivas adequadas apenas para mulheres. (Alunos da 8 Ano).

Fonte: Os autores (2018).

Entre os alunos do 9- Ano, 42\% (19) dos meninos e $60 \%$ (27) das meninas concordam em que as atividades devem ser mistas - meninos e meninas juntos. Outros $13 \%$ (06) e $02 \%$ (01) das meninas pensam que as atividades devem ser separadas devido à fragilidade das meninas. Outros ainda 08\% (04) dos meninos e 02\% (01) das meninas concordam em que as atividades devem ser separadas de acordo com o sexo. E finalmente, $33 \%$ (15) dos meninos e $37 \%$ (17) das meninas concordam em que as atividades sejam mistas, com adaptação das regras para atender às meninas. Dentre as opções que tiveram mais votos, somando-se meninos e meninas, temos $51 \%$ (46) alunos que concordam em que as atividades devem ser mistas; e 35\% (32) dos alunos acham que devem ser mistas mas com adaptação das regras para atender as meninas (Gráfico 12).

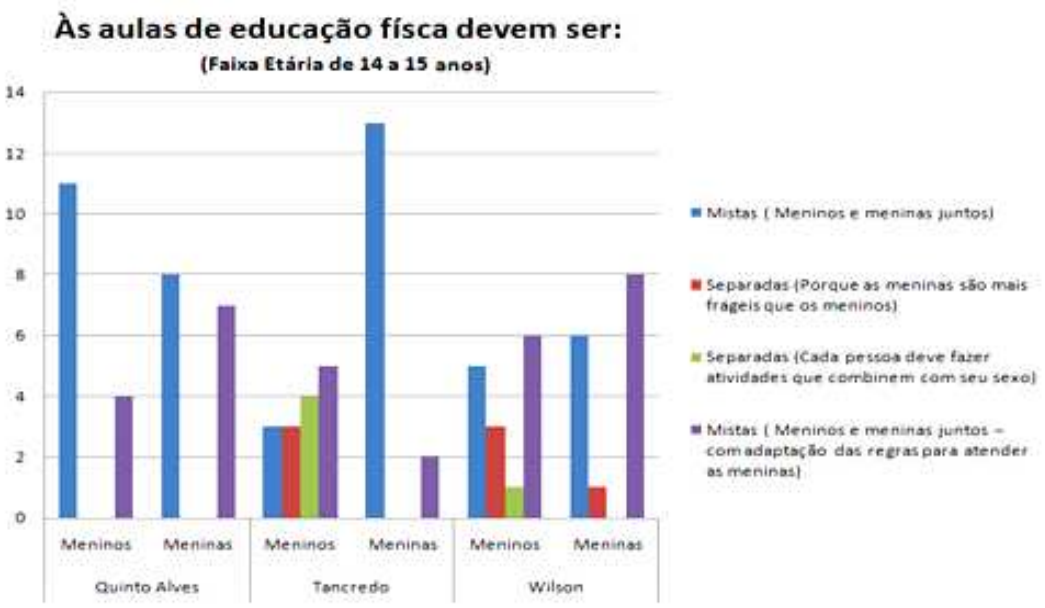

Gráfico 12 - São atividades desportivas adequadas apenas para mulheres (Alunos do 9․ Ano).

Fonte: Os autores (2018). 


\section{Análise dos Resultados}

A amostra do estudo contou com 270 alunos, de ambos os sexos, do $7^{\circ}$, $8^{\circ}$ e e $9^{\circ}$ anos do ensino fundamental da rede pública. Em cada escola, foram selecionados 30 alunos por série, 15 do sexo masculino e 15 do sexo feminino, sendo a escolha aleatória. Cada aluno só participaria se realmente quisesse. Cada uma das perguntas do questionário utilizado tinha como meta apurar o nível de percepção dos alunos pesquisados acerca da temática deste trabalho e o que eles pensavam a respeito dela.

Nos gráficos acima, a análise dos dados foi feita de três formas: primeiro considerando cada turma individualmente, favorecendo a percepção das respostas a partir da faixa etária e da turma (nível de escolaridade). Em seguida, todos os alunos de uma determinada série foram considerados em conjunto, favorecendo a comparação de opiniões entre alunos de uma mesma série e faixa etária, porém de escolas diferentes. $E$ finalmente, todos os alunos que escolheram uma determinada opção, foram somados (meninos e meninas juntos) para a obtenção geral de dados pertinentes a esta determinada questão e para apurar quais questões tiveram maior número de escolhas.

A seguir, a análise dos resultados se dará somando-se isoladamente meninos e meninas, sem levar em conta as séries às quais pertençam, já que é possível visualizar os resultados nos gráficos.

Segundo os resultados referentes à primeira questão [O que você entende por gênero?], 36\% (49) dos meninos e 38\% (52) das meninas responderam que gênero se trata do sexo biológico. Outros $25 \%$ (35) dos meninos e $27 \%$ (37) das meninas associam gênero a orientação sexual. E outros 37\% (51) dos meninos e 34\% (47) das meninas associaram gênero aos padrões sociais impostos a partir do sexo biológico - sendo esta a opção ideal.

$\mathrm{Na}$ questão seguinte [São atividades que você considera adequadas apenas para homens], apenas $0.5 \%(01)$ dos meninos e 02\% (03) das meninas acham que cozinhar, lavar, passar e cuidar da estética são atividades adequadas unicamente para homens; nenhum dos meninos e 1.5\% (02) das meninas, disseram que cozinhar, passar e pilotar aviões é que são as atividades indicadas somente para homens. Ainda, 18\% (25) dos meninos e nenhuma das meninas, respondeu que pilotar aviões, liderar grandes empresas e jogar futebol são atividades apenas para homens. E 82\% (112) dos meninos e 92\% (126) das meninas responderam que homens e mulheres podem fazer quaisquer atividades relacionadas na questão.

$\mathrm{Na}$ terceira questão [São atividades que você considera adequadas apenas para mulheres], 01\%(02) dos meninos e 02\% (04) das meninas concordam que vôlei, futebol e pilates sejam atividades apenas para mulheres; enquanto $15 \%$ (21) dos meninos e $04 \%(06)$ 
das meninas acham que seja vôlei, pilates e peteca. Ainda, 01\% (02) dos meninos e nenhuma das meninas, disseram que futebol, boxe e pilates são atividades apenas para as meninas enquanto $79 \%$ (108) dos meninos e $91 \%$ (125) meninas opinaram que homens e mulheres podem fazer quaisquer dessas atividades.

$\mathrm{Na}$ última questão [As aulas de Educação Físicas devem ser...], 43\% (59) dos meninos e $56 \%$ (77) meninas disseram que as atividades das aulas de Ed. Física devem ser mistas; $18 \%$ (25) dos meninos e 05\% (07) das meninas, disseram que tem que ser separadas (meninas são mais frágeis). 10\% (14) dos meninos e $0.5 \%$ (01) das meninas concordam que cada aluno deve fazer atividades apropriadas a seu sexo, e finalmente, $27 \%$ (37) dos meninos e $36 \%$ (49) das meninas concordam que devem ser mistas, mas com regras adaptadas para favorecer as meninas.

Conforme percebemos nos dados obtidos, um percentual significativo de alunos (as), não tem percepção do que de fato significa o termo gênero, sendo ínfima a diferença de percepção entre meninos e meninas. Tomadas de forma isolada, as tabelas demonstram que as meninas têm uma vantagem ligeiramente superior aos meninos neste quesito, que, quando muito, empatam com elas. No entanto, se somarmos os alunos de ambos os sexos que sabem o que de fato significa gênero separando-os daqueles que o associam a sexo biológico ou à orientação sexual, veremos que apenas 36\% (101) considerando alunos de ambos os sexos, sabem o que é "Gênero". Enquanto 62\% (170) dos alunos o associam a sexo biológico ou à orientação sexual. Ora, isto não chega a ser um problema, levando-se em conta que nas respostas subsequentes, a maioria dos alunos demonstrou uma postura bastante libertária ao admitirem que homens e mulheres possam fazer quaisquer atividades (proposta que embasa as questões $\mathrm{n}^{\circ} 02$ e $\mathrm{n}^{\circ}$ 03), o que sugere que devem ter uma postura mais flexível frente aos padrões culturais que determinam os papéis sexuais.

$\mathrm{Na}$ questão no 04, ficou patente que compreendem que não deve haver separações entre os sexos durante as atividades de Ed. Física, já que 50\% (136) entre meninos e meninas disseram que as atividades devem ser mistas, o que sugere que não tenham preconceitos relativos a gênero. Na última questão, é interessante notar que $31 \%$ (86) dos alunos, contando-se meninos e meninas, disseram que as atividades deveriam ser mistas, mas com adaptação das regras para favorecer as meninas, o que sugere que tenham alguma noção de equidade, isto é, percepção de que a fragilidade das meninas (que não deve ser confundida com fraqueza) requer adaptações na prática que viabilizem uma participação de ambos os sexos, sendo esta uma oportunidade que o professor tem de "[...] ser pluralista e democrático [criando] condições mais favoráveis para o esclarecimento e informação". (BRASIL, 2001, p. 130).

Sendo assim, o aluno deve ser estimulado a participar de atividades corporais, estabelecendo relações equilibradas e construtivas com os outros, reconhecendo e 
respeitando características físicas e de desempenho de si próprio e dos outros, sem discriminar por características pessoais, físicas, sexuais ou sociais [...] (BRASIL, 1997).

Logo, percebemos que, algumas das hipóteses que foram levantadas não se confirmaram. Por exemplo, nem sempre o desconhecimento do real significado do termo gênero implica na incapacidade de questionamento dos modelos socioculturais dos papéis de gênero, pois, como vimos, embora 36\% (49) dos meninos e 38\% (52) das meninas tenham respondido que gênero se trata do sexo biológico, $82 \%$ (112) dos meninos e 92\% (126) das meninas responderam que homens e mulheres podem fazer quaisquer atividades relacionadas na questão, demonstrando que a grande maioria dos pesquisados tem noção da importância de se respeitar as escolhas individuais.

Aos alunos que ainda ignoram as terminologias inerentes à sexualidade, sugere-se que haja planejamento por parte dos docentes que atuam nas escolas pesquisadas, através da exposição dos conteúdos inerentes à sexualidade, trabalhando-os em caráter de interdisciplinaridade e transversalidade, que são os mais indicados para lidar com tais temáticas, conforme demonstram as

[...] experiências pedagógicas brasileiras e internacionais de trabalho com educação ambiental, orientação sexual e saúde [que] têm apontado a necessidade de que tais questões sejam trabalhadas de forma contínuas e integradas, uma vez que seu estudo remete à necessidade de se recorrer a conjuntos de conhecimentos relativos a diferentes áreas do saber (BRASIL, 2001, p.36).

\section{Conclusão}

De maneira geral, os dados encontrados neste estudo mostram que os educadores físicos são na maioria indivíduos jovens, solteiros, prevalentemente homens com ocupação dividida entre o S.A e P.T em jornadas de trabalho curtas e baixa remuneração, mas que não tendem a se especializar para continuarem a desempenhar suas funções. Os dados revelam uma satisfação geral classificável como de "Sucesso" segundo os parâmetros de Spínola \& Pereira (1976, p. 26-32) que se estendem entre os indicadores de Domínio Físico, Psicológico, de Relações Sociais e Meio Ambiente. O cenário das academias de musculação revela mudanças ao longo do tempo (FURTADO, 2009), que condicionam adaptações condicionadas ao seu público e aos profissionais que devem se adaptar à elas.

Numa sociedade democrática, que se caracteriza pela liberdade de pensamento, e que abriga em seu seio indivíduos de diversas culturas, comportamentos e crenças é natural que existam divergências sobre diversos assuntos. No entanto, diante da violência que emerge da ignorância e das desigualdades sociais, a escola é chamada a exercer seu magistério a favor da vida, trabalhando pela diversidade em todos os níveis, despertando nos discentes a capacidade de questionar os modelos sociais nos quais estão inseridos, 
fomentando a autonomia que Ihes permita transformar sua realidade através da percepção das próprias potencialidades e capacidades.

A Educação Física, que cuida da Cultura Corporal de Movimento, cumpre um importante papel nesse sentido, pois tem a possibilidade, através de uma práxis bem planejada, de despertar nos alunos a disposição de conviver com as diferenças a partir do reconhecimento daquilo que os irmana: Sua corporeidade/humanidade. De fato, os jogos e atividades coletivas retratam o que acontece fora dos muros da escola: Ninguém consegue nada sozinho. Tanto nos campeonatos escolares quanto na vida, nem sempre é possível escolher quem serão os parceiros de time, nem ter garantias de que se ficará de pé durante todo o jogo. $E$ caindo, aprende-se que, a menos que se levante o jogo pára. $E$ dependendo da possível gravidade dos ferimentos, também se aprende que não se escolhe aquele que prestará socorro.

A Pedagogia Esportiva Escolar se torna, portanto, ferramenta de potencial humanizadora ao propor através de seus cinco pilares que, a promoção de um mundo melhor só é possível através da "construção coletiva", que requer a inclusão de todos e respeito à diversidade; mundo cuja base se assente na educação integral conduzindo os sujeitos rumo à autonomia - chave para uma vida de contínuo crescimento, aprendizado e cidadania.

\section{Referências}

BRASIL. Constituição (1988). Constituição Federal da República Federativa do Brasil. Brasília, DF: Senado Federal: Centro Gráfico, v. 1, p. 292, 1988.

LDB/9394/1996. Lei de Diretrizes e Bases da Educação Nacional. Lei número 9394, 20 de dezembro de 1996. Estabelece as diretrizes e bases da Educação Nacional. Brasília: MEC, 1996.

BRASIL. Ministério da Educação. Nota Técnica no 24/2015. Brasília. MEC. 2015. Disponível em: <http://www.spm.gov.br/assuntos/conselho/nota-tecnica-no-24-conceito-genero-no-pnemec.pdf>. Acesso em Set de 2018.

BRASIL. Parâmetros Curriculares Nacionais (PCNs). Introdução. Ensino Fundamental. Terceiro e Quarto Ciclos. Brasília: MEC/SEF, 2001.

BRASIL. Parâmetros Curriculares Nacionais (PCNs). Educação Física. Ensino Fundamental. Terceiro e Quarto Ciclos. Brasília: MEC/SEF, 2001.

BRASIL. Parâmetros Curriculares Nacionais (PCNs). Apresentação dos Temas Transversais e Ética. Ensino Fundamental. Terceiro e Quarto Ciclos. Brasília: MEC/SEF, 2001. 
BRASIL. Parâmetros Curriculares Nacionais (PCNs). Pluralidade Cultural e Orientação Sexual. Ensino Fundamental. Terceiro e Quarto Ciclos. Brasília: MEC/SEF, 2001.

BRITO, Patrícia.; REIS, Lucas. Por pressão, planos de educação de 8 estados excluem 'ideologia de gênero'. Folha de São Paulo, 25 Jun. 2015. Disponível em:< https://www1.folha.uol.com.br/educacao/2015/06/1647528-por-pressao-planos-de-educacaode-8-estados-excluem-ideologia-de-genero.shtml I>. Acesso em: 10 de Set. de 2018.

CABRAL Francisco; DÍAZ, Margarita. Relações de gênero. In: Secretaria Municipal de Educação de Belo Horizonte: Fundação Odebrecht. Cadernos afetividade e sexualidade na educação: um novo olhar. Belo Horizonte: Gráfica e Editora Rona Ltda, v. 1, p. 142-150, 1998.

Declaração Universal dos Direitos Humanos. 1948. Disponível em: <https://www.unicef.org/brazil/pt/resources_10133.htm>. Acesso em: Set. 2018.

EGYPTO, Antônio Carlos.; EGYPTO, Marta.; Papéis sexuais. In: BARROSO, Carmem.; BRUSCHINI, Cristina.; Sexo e Juventude: Como discutir sexo e sexualidade na escola. $8^{\text {a }}$ Edição. São Paulo: Editora Cortez, v. 5, p. 50-54, 2002.

LANG. Jeter.; ZANCHET. Ricardo.; DOMINGUES, Maria José Carvalho Souza. Compreensão de leitura a luz de teste cloze: comparação entre ingressantes e concluintes do curso de Administração. Convibra 07. Blumenau- SC, v. 1, p. 1-13. 2007 LOURENÇO, Benito.; QUEIROZ, Lígia Bruni. Crescimento e desenvolvimento puberal na adolescência. Revista Médica. (São Paulo), v. 89, n. 2, p. 70-75, 2010.

MUSSKOPF, André Sidnei. Quando gênero e sexualidade se encontram. Revista Tempo e presença digital, v. 3, n. 8, p. 82-86, 2008. 